REVISTA CHILENA DE LITERATURA

Noviembre 2009, Número 75, 309 - 315

\title{
ENTREVISTA A JORGE GUZMÁN
}

\author{
Por Leonidas Morales T. \\ Universidad de Chile
}

L.M. Yo entiendo que el cambio que se produjo a fines de la década de 1950 y a lo largo de toda la del 60 en los estudios de literatura desde el ámbito de la Universidad de Chile (y desde ahi a las demás universidades), es un cambio muy profundo desde el punto de vista de los anclajes teóricos. Yo entré a la universidad en 1957 y alcancé a tener la experiencia de algunos profesores anteriores. Uno de ellos, Ricardo Latcham, se iba formalmente como Embajador creo que a Uruguay, y lo reemplazó por un semestre otro profesor, de apellido Durán. Y después, la experiencia de empezar a tener clases con ustedes, contigo, con Félix Martínez, con Cedomil Goic. ¿Cómo llegaste tú a la Universidad de Chile, de dónde venías?

J.G. Yo venía del Instituto Nacional y llegué bastante temprano como Ayudante de Antonio Doddis. No nos entendíamos demasiado. A pesar de que todos ellos eran gente que sabía mucho. El saber enciclopédico de Latcham, por ejemplo, era envidiable. Tú le preguntabas cualquier cosa y te daba los datos, libros publicados, dónde y cuándo vivió el autor, bibliografía principal, etc. También Doddis tenía una información enorme sobre literatura española medieval y clásica. $\mathrm{O}$ sea, era gente muy respetable. Pero de un tipo de saber que a nosotros no nos gustaba. Te voy a dar un ejemplo extremo. Tuve un examen de española una vez. Nos habían dado entre otras unas lecturas de Azorín. Y yo, con mi tonta arrogancia de entonces, me presenté al examen y el profesor me empezó a interrogar sobre las fichas de lo que había leído, y me dice ¿usted leyó tal ensayo de Azorín? Sí, pero no me acuerdo de nada, le dije. ¿Y si lo ha leído, cómo no se va a acordar? ¿Y este otro de Azorín, lo leyó? Lo leí, pero tampoco me acuerdo de nada... ¿Y cómo puede ser? ¿Se acuerda de los otros? Sí, claro, de los otros me acuerdo. ¿Y cómo no se acuerda de Azorín? Sabe, le dije yo, con eso de chiquillo insolente, Azorín me parece un majadero. Y el Profesor Auxiliar, que era Ricardo Benavides, se paró y se puso a aplaudir. Y este

Profesor Titular, Departamento de Literatura, Facultad de Filosofía y Humanidades, Universidad de Chile. Los cursos o seminarios que da y los numerosos artículos y la docena de libros que ha publicado giran, fundamentalmente, en torno a la obra de determinados escritores chilenos, claves dentro de la historia de nuestra literatura (Nicanor Parra, Violeta Parra, José Donoso, Diamela Eltit, Roberto Bolaño), y en torno a la problemática de los géneros de no ficción, o "referenciales" (sobre todo la carta y el diario íntimo). 
profesor, con muy justa razón, porque era una insolencia mía hacia él y sus saberes, durante los siguientes diez años, en cada marzo, iniciaba el curso contando esta misma anécdota. Bueno, eso te dice algo. Pero, al mismo tiempo, estos profesores fueron los que posibilitaron que nosotros hiciéramos otra cosa. Claro. Porque nosotros, con Félix, con Cedomil, lo que hicimos fue enseñarles a leer a los alumnos. Nada más. Eso nos lo enseñaron básicamente ellos, y yo creo que esa enseñanza basta, digamos, para llegar a los niveles de Doctorado. Eso lo aprendimos de ellos, por lo menos yo.

L.M. Sí, está bien. Pero yo recuerdo que Latcham, en sus clases, que eran muy entretenidas, no distinguía entre texto e incidentes biográficos, politicos, y metía todo en la misma lavadora. En cambio, lo que yo empecé a ver, y que lo veo con más claridad a posteriori, diría, es que ustedes empezaron a enseñar a leer a la luz de una teoría, la contemporánea, la surgida del horizonte y del contexto de las vanguardias, y que en Chile simplemente no había llegado a la universidad, y que ustedes estaban, diriamos, haciendo entrar.

J.G. Yo creo que tienes toda la razón. Lo que pasa es que aprender formalmente a leer necesita un armado conceptual. Nosotros ya no podíamos leer inocentemente. Debíamos leer con un armado conceptual. Estos armados sirven mientras sirven y después quedan como parte de una estructura mental, nada más, pero se pierden objetivamente. Ya estaba el estructuralismo en autores como Dámaso Alonso, pues realmente el modo de leer de Alonso, y los demás del método estilístico, era prácticamente el mismo que usaron los estructuralistas después, solo que sin los conceptos de los estructuralistas. Leían impecablemente, pero ya no podía justificarse la inocencia de su lectura filológica. Habían cambiado los tiempos. Ahora, los primeros exégetas de Góngora, cuatro siglos antes, leían también impecablemente. La suya era una lectura filológica excelente, por respeto al texto. De ahí, me parece, vino la generación de Alonso y luego los estructuralismos. Con todo, el primero en aplicar aquí conceptos estructurales a la narrativa fue Félix y él los trajo de Alemania. Los demás, creo, importábamos conceptos de Francia. Pero, te repito, en esencia, se trató meramente de enseñar a leer, y estas conceptuaciones eran valiosísimas auxiliares de la lectura, nada más. Temo que ahora el interés por leer realmente, respetando el texto, se esté extinguiendo rápidamente. La mayor parte de los escritos académicos sobre otros textos que encuentro (afortunadamente no todos) son manifestaciones de un profundo desinterés por lo que se lee. Pienso, por ejemplo, en casi todo lo que se escribe sobre la Mistral o sobre Vallejo. El académico normal no está interesado realmente en el gran poema. En lo que está interesado es en producir otro "paper", que le va a salvar el sueldo o subírselo al año siguiente. En el campo de la literatura, son muy raros los académicos que trabajan porque les interesa el tema y son mayormente jóvenes.

L.M. Desde el punto de vista del lector hay un fenómeno paralelo. En la segunda mitad de la década de 1950 y en la década siguiente, ¿cómo se leía? Se leía desde una especial manera de estar en el tiempo, de vivirlo como tiempo histórico. Para un lector de entonces, el presente era impensable sin su componente utópico, sin esa sociedad y esa cultura soñadas, deseadas, que parecían estar muy cerca, a la vuelta de la esquina. La literatura que aparece por esos tiempos, la del "boom”, nos conquistó porque concordaba con este tiempo cotidiano abierto a la seducción de un futuro. Y las lecturas de 
teoría, de ensayo literario, cultural, se hacían desde el mismo contexto. Tú tienes razón. Yo recuerdo que a los españoles casi uno no los leía. Uno leía a los alemanes, ingleses, franceses. Esa manera de estar en el tiempo como lector es lo que hoy día no ocurre. La gente joven, el profesor joven, en la universidad ¿no?, parece hoy el sujeto de un proyecto de fuerte inmediatez, deshistorizado, asociado a expectativas de ascenso académico, de figuración (vía cargos, congresos, becas, etc.), de "hacer curriculum", expectativas a la vez de ingresos y de consumo. Pero no es un sujeto interesado profundamente en la literatura como fuente de un saber que te compromete vitalmente, individual y socialmente.

J.G. Mira, yo tengo casi exactamente la misma impresión, pero creo que las pocas excepciones son mayormente jóvenes. Lo normal, sin embargo, es otra cosa. Yo conozco una señora que estudió en lugares prestigiosos, pero dice tranquilamente que no le interesan en absoluto los textos que "estudia", que para ella son pre-textos para hablar de otra cosa. Lo que le interesa es la otra cosa. Bueno, poéticamente, así no vamos a ninguna parte. Imagínate que un biólogo dijera que no le interesa para nada la biología, que simplemente anda mirando por el microscopio "para otra cosa". Creo que hay también este espantoso cambio de valoración. El triunfo del neoliberalismo, que se está hundiendo ahora, es parte del panorama, me parece. Solo gentes muy tozudas defienden la viabilidad del neoliberalismo, o de lo que se llamó socialismos reales. Creo que nos encontramos en un tiempo terrible. Fracasó el neoliberalismo en la crisis actual y en el enorme descontento de quienes lo hemos sufrido. Pero también fracasó una forma de administración socialista. Fracasó sin lugar a dudas. Eso no significa, creo, que haya fracasado el socialismo. Fracasó esa manera de hacer socialismo. Pero fracasó, y no se ha propuesto otra manera viable.

\section{L.M. No hay ninguna.}

J.G. No hay ninguna claramente formulada. Después, fracasó el liberalismo en su forma extrema, el liberalismo mundializado en que vivimos ahora. Y lo que quedó del discurso del neoliberalismo, fue un solo valor, el dinero. Los destinos que se les ofrecen al noventa y nueve coma nueve, nueve, nueve por ciento de los jóvenes de hoy día son nada más que dos: ser pobres o ser ricos. Ahora, en esas condiciones, ¿a quién diablos le va a interesar la poesía, caramba? ¿O la creación narrativa? ¿O el teatro? ¿O cualquier otra cosa teórica? Hoy día se están vendiendo obras de arte a precios enormes, pero eso no es estimación por el arte, sino especulación. Leí por ahí que se había vendido en algo así como quince mi libras esterlinas una estatua de la Virgen María chorreada con excrementos, y esto parecía muy novedoso e importante al señor que la compró.

L.M. Baudrillard analiza muy bien el estado actual de la modernidad cultural, el "posmoderno", y las condiciones que hacen posible hechos como el que tú narras, el de la estatua de esa Virgen María y su venta. En una de las conferencias que dio en Caracas en 1994, Baudrillard decia que el mundo se ha vuelto pura "inmanencia”, es decir, pura superficie y transparencia, y que por lo tanto ya no tiene un "valor estético" propiamente tal. Esta situación es particularmente impactante para gente como nosotros, que venimos de un tiempo en que el mundo precisamente tenía un valor estético porque se abría a la "seducción" y al "deseo" de un futuro cuya inminencia marcaba el presente con un estado de "entusiasmo". Ahora, en mi memoria, ese tiempo es inseparable de 
los cambios de enfoque en los estudios de la literatura, ocurridos en la Universidad de Chile desde la segunda mitad de la década de 1950. Tú, Félix y Goic, nos enseñaron a ver en la literatura, primero y ante todo, un texto, para nada ajeno al tiempo y a la historia, a las expectativas de vida y sociedad del lector, y, segundo, a leerlo a la luz de su teoría contemporánea. Al margen de mi interés de siempre por la literatura, esa manera de leerla, que yo sigo practicando, no existía antes de ustedes, la impusieron ustedes, se la debemos a ustedes, la aprendimos como alumnos de ustedes.

J.G. Me alegro mucho... y creo que tú la practicas excepcionalmente bien.

L.M. Ahora, yo sé que tú tenías buenas relaciones personales con Félix, con Goic. Dime una cosa, ¿conversaban ustedes sobre esos cambios? ¿Tenían conciencia de ellos?

J.G. Mira, la teníamos, pero en cuanto a conversaciones, más que meditar o sentarnos a hacer programas de cómo hacer las cosas, descubríamos al conversar que coincidíamos en nuestros comentarios en muchas cosas básicas. Y así fue despejándose un pensamiento, el de nosotros. Porque hablando, digamos, de lo mal que lo estaba haciendo Zutano o Zutana, o de lo lamentable de que tal profesor, que sabía tantas cosas, no fuera capaz de integrarlas en un armado conceptual, fue asomando un programa naturalmente. Además, era un momento bastante feliz. Como tú has dicho, el mundo era otro. Teníamos, quizá por eso, mucho material. Era cosa de conseguirse una bibliografía y uno estaba en comunicación con el mundo entero en relación con este objeto que nos interesaba tanto: el texto. Por ese camino llegamos a estar al día en la bibliografía que entonces se manejaba. Yo me acuerdo que una vez vino un docente que llegó con el gran prestigio de ser el más joven docente de Alemania. En una comida, se puso a hablarnos magisterialmente de Sartre, y fue morigerado de inmediato, porque ni manejaba tanta bibliografía como afectaba, ni su lectura iluminaba nada. De modo que sí, estábamos al día con lo que pasaba en nuestro campo.

L.M. Bueno, yo ya te dije que para nosotros el cambio que introdujeron ustedes en su enseñanza como profesores produjo una separación de aguas con lo que se hacía hasta entonces. Ahora, tampoco eso fue azaroso: ustedes tenían las competencias para hacerlo. Sé que Goic hizo un doctorado en la misma Universidad de Chile. Sé también que Félix se habia ido a Alemania a hacer su Doctorado, y que fue a su regreso que lo tuvimos como profesor y figura del cambio de que hablamos. Pero de tu recorrido en ese plano no sé mucho.

J.G. Bueno, me fui a Estados Unidos el 58 y allí aprendí mucho. Pero me gusta decir que yo tenía ya un mapa relativamente claro de mi campo y me lo habían dado en Chile.

\section{L.M. Tú fuiste a Iowa, ¿no?}

J.G. Sí. Era muy bueno Iowa en ese momento, y lo es todavía. Muy buena universidad en varios campos. Estaban ahí Wellek y Warren, en teoría literaria, Roggiano, en literatura hispanoamericana. De Chasca, en medieval española. En teatro isabelino estaba Maxwell. En griego, Nybbaken. En grabado, Lazansky. En física, Van Allen, el de los famosos "cinturones". Y muchos más. 


\section{L.M. Tú hiciste un doctorado.}

J.G. Hice un doctorado e hice clases, las dos cosas. Las clases tengo que agradecérselas a Edmund de Chasca, que me favoreció con esa tarea.

L.M. Por esos años, los profesores nativos, yanquis, de literatura hispanoamericana tendian a ser especialistas a ultranza. En Los Angeles, en la UCLA, donde enseñé, conoci a un especialista en Carlos Fuentes. Y solo sabía de Carlos Fuentes. Podía tener, por ejemplo, el último artículo sobre Fuentes aparecido en un diario de Hong-Kong, pero no manejaba mucho las conceptualizaciones, las teorías, los grandes temas culturales del momento, etc. Creo que eran en general bastante malos.

J.G. En general, eran malos.

L.M. Habia sí, te hablo de la década del 60, cuando yo estuve allá la primera vez, mucha gente de afuera, de Europa, españoles, por ejemplo.

J.G. Ahora, había españoles buenos y españoles que no lo eran tanto. No todos eran muy buenos. Y los latinoamericanos tampoco eran todos óptimos.

L.M. De los latinoamericanos, ¿quiénes estaban? ¿Torres-Rioseco? Alegría.

J.G. Alegría, en California. Estaba el gran Américo Castro. Claro, él no era latinoamericano...

\section{L.M. Estaba en Princeton.}

J.G. Sí. Pero había algunos menos que dudosos. Las universidades norteamericanas han hecho un poco el mismo tránsito que las nuestras hacia maneras dudosas de enfrentarse a la literatura, y algunas empezaron antes. Afortunadamente, hay universidades norteamericanas (no muchas) que siguen graduando gente buena.

L.M. Volviendo a la Universidad de Chile y a aquellos años que estábamos recordando. Aparte de las afinidades evidentes, de amistad entre ustedes...

J.G. Bueno, Félix y yo veníamos del mismo colegio, del Instituto Nacional.

L.M. Uno percibía también diferencias, estilos distintos, por ejemplo, en el diálogo con los alumnos. Para mí, Félix fue siempre una persona amistosa, y especialmente amistosa con el pensamiento ajeno, discrepante. En cambio Goic tenía una actitud muy magistral, de autoridad, que a uno...

J.G. Los cortaba, decían algunos alumnos, pero no eran los mejores.

L.M. Lo cortaba un poco.

J.G. Yo no fui su alumno por cierto ni asistí a sus clases, pero en privado era un tipo dicharachero, bromista, claro y leal. Yo no supe de la opinión reticente de algunos alumnos hasta después.

L.M. Ahora, entrando ya en el capítulo de sacar cuentas, yo no sé qué balance harías tú de lo que ustedes tres instalaron o contribuyeron a instalar en los estudios de literatura en la Universidad de Chile. A la luz, claro, del estado actual de estos estudios. 
J.G. Sobre eso no tengo opinión... Me da la impresión, por las revistas que leo, que somos ciudadanos de un paisito pobre, perdido en el extremo de América, con pretensión de que acá se originan cosas, pero por lo demás dentro de un mundo que nos rebasa y al que le interesamos solo ocasionalmente. De cuando en cuando, incluso por algún motivo detestable, como en el caso de Pinochet. Ahora, esta situación de secundariedad afecta sin duda a los estudios literarios. También los afectan otras cosas: la política, la economía, las nuevas orientaciones de la sociedad. ¿Por qué no está aquí la lectura de moda? Por muchísimas razones que hicieron perderse las bases centrales de muchas cosas. Por eso, la lectura académica que hacen hoy día suele ser liviana, y a menudo de tonterías.

L.M. Desde hoy, uno puede entender el desenlace de procesos que en el momento en que estaban en desarrollo no los hubiera imaginado. Yo no imaginé, por ejemplo, que la Unidad Popular, nuestro "Mayo francés", terminaría como terminó en 1973. Desde la perspectiva de ustedes, tuya concretamente en este caso, ¿qué percibian en esos años? Me refiero a una percepción del futuro de lo que estaba poniéndose en marcha.

J.G. Francamente, un grave riesgo de deterioro. Yo era partidario de Salvador Allende, y voté por Allende... Tenía muchos amigos, y tenía más amigos de derecha que de izquierda en el ámbito social. Tenía muchos amigos de izquierda también, pero de otro tipo, como Guillermo Núñez o Eduardo Martínez. Y salió Allende. Y al día siguiente, me junté con algunos amigos de derecha (que pronto dejaron de serlo). Me convidaron a algo, y todos me miraban como al ejemplar más raro de Chile. Porque ellos andaban con la cara larguísima. Y yo lo que decía era que la cosa no iba a terminar nada de bien. No por culpa de la izquierda, sino porque había una derecha golpista y porque al lado había un Imperio gigante en contra. De modo que sí, yo percibía la amenaza del deterioro político. Y también que la Universidad no iba por buen camino, y que no llegaría a otra parte que el país entero. Pero nunca me imaginé cuál era el destino concreto y espantoso que iba a tener.

L.M. Jorge, además de profesor prestigioso de la Universidad de Chile, tú has sido también autor de notables libros de crítica literaria latinoamericana, trabajos que desde luego conozco y cuyas tesis además suscribo. Pero además del ensayo, un género, diría, previsible en quien se dedica a los estudios literarios, tú también has practicado otro género, no tan previsible sin duda, como lo es la novela. Eres autor de varias novelas. Para terminar, me gustaría conocer tu reflexión sobre la recepción de estas novelas.

J.G. En cuanto a la recepción de mis novelas en Chile, y también en otras partes, mi reflexión estaría bien resumida por un señor que escribió un artículo, no me acuerdo en qué periódico, y que decía: "Este autor es un bestseller académico". Efectivamente, la mayor parte de mis lectores, que no son tan pocos después de todo, han sido gente del medio académico. En cuanto a lo que yo quiero de la literatura, no es "hablar en necio para darle gusto", a un público que Lope entendía ser de tontos. Traducido a un lenguaje más respetuoso, creo que lo que Lope estaba diciendo era que no quería escribir literatura alambicada. El talento para llegar a grandes públicos es una cosa que yo admiro. Me encantaría poder hablar en, digamos, un lenguaje que deleitara a todo el mundo. Me encantaría poder hacerlo. Y encuentro que es un gran talento el de la gente que tiene esa 
cualidad. Yo he conseguido poco de la literatura, y eso no me desagrada, más bien me gusta: conserva la independencia y la tranquilidad necesarias. Tal vez yo tenga una idea medio ñoña de la novela. Toda la evolución del género novela ha girado alrededor del realismo, algo que se llama "realismo", muchas comillas, pero "realismo". Es decir, todos los esfuerzos que han hecho los novelistas a lo largo de toda la historia del género, son esfuerzos hacia la realidad. Que han terminado, bueno, donde sabemos. Yo sigo por ahí y seguiré. No entiendo escribir de espaldas a los problemas que entiendo reales. Lo otro que pienso yo de la novela chilena... Es decir, no juzgo si esto es bueno... Hay autores que me gustan y otros que prefiero no leer porque... a la décima página me doy cuenta de que no va a andar la cosa para mi gusto.

L.M. Pero hay nombres en la novela chilena que me parecen nombres imprescindibles en la medida en que por ellos pasan de alguna manera las lineas principales del desarrollo del género en su etapa contemporánea. Pienso por ejemplo en José Donoso y en algunas novelas suyas que me gustan mucho...

J.G. A mí también, pero no me gustan todas, y no me gustan algunas de las más famosas...

L.M. ¿El lugar sin límites...?

J.G. Me parece una linda novela.

L.M. ¿El obsceno pájaro de la noche...?

J.G. La verdad, no tanto.

L.M. ¿Casa de campo?

J.G. Sí, Casa de campo sí.

L.M. Además de Donoso, también me parece un nombre imprescindible Diamela Eltit.

J.G. La encuentro también la narradora más seria que tenemos..., o de las más serias.

L.M. No sé si has podido leer a Bolaño, para mí otro nombre imprescindible.

J.G. Me gusta Bolaño, me gusta, ponte tú, mucho Los detectives salvajes, pero... creo que le sobran páginas. En 2666, creo que sobra todavía más. Pero hay que leerlo tal como está, y tiene muchas páginas maestras. Supongo que si Bolaño no hubiese estado gravemente enfermo y hubiera tenido tiempo, habría salido con su proyecto original de producir con ese material cinco novelas. Desgraciadamente no tuvo tiempo.

Déjame agregarte un nombre, Cynthia Rimsky, novelista joven que me parece la mejor de su generación. Hasta ahora ha escrito dos novelas: Poste restante y La novela de otro. Creo que la tercera está en prensa. Y asombra que a las dos publicadas no se les haya concedido el lugar y la atención crítica y mediática que merecen. Todas son muy buenas y la tercera muestra, encima, un claro progreso. 